\title{
Discussions on Improving the Teaching Quality of Fundamental Chemistry Experiment Course
}

\author{
Boquan Jiang*, Ting Liu, Lei Xiong, Xiaoxing Wu, Zhengping Chen \\ Department of Biology and Chemistry \\ Institute of Science \\ Nanchang University College of Science and Technology, \\ Nanchang, Jiangxi, 330029 \\ China \\ *Corresponding author: jbq_win@163.com. mobile phone number: 13397080986
}

\begin{abstract}
Improving the teaching quality of fundamental chemistry experiment (FCE) course is one of the important ways to cultivate the creative talents in the universities and colleges. In consideration of the present problems in the teaching of FCE course, several measures are put forward in this paper, which involves: increasing the students' understanding of importance of FCE course and interests in learning FCE course, cultivating the students' study style of combining theory with practice, implementing the mode of open experiment teaching and establishing the scientific experimental assessment system. The implementation of these measures greatly inspires the students' motivation of autonomous learning and improves the teaching quality of FCE course.
\end{abstract}

Keywords- Fundamental chemistry experiment; basic chemistry experiment; teaching quality; teaching reform; innovation

Chemistry is a natural and applied science based on experiments. The experiment plays a bridge role in chemistry teaching. The students can see the vivid and intuitive phenomena, deeply know the compositions, structures and properties of the substances, and grasp various of operation skills through experiments. Chemistry experiments are able to help the students to understand the concepts, stimulate the students' interests in learning, motivate the students' activities of study, cultivate the students' serious scientific attitude and develop the students' intelligence [1-2]. Fundamental chemistry experiment (FCE) course is a comprehensive curricurum system involving inorganic chemistry experiment, organic chemistry experiment, physical chemistry experiment and analytic chemistry experiment and an important basic experiment course in independent colleges, which plays an important action for cultivating the advanced applied and creative talents. Our college was built in 2001. The FCE course consists of university chemistry experiment ( inorganic and analytic chemistry experiments ) and organic chemistry experiment. This course is opend to the non-chemistry majors, such as applied chemistry, pharmaceutical engineering, biologic engineering, biologic technology, polymer materials and engineering, environmental engineering and water supply and drainage. At present, there exist several problems in the teaching of FCE course as follows. ( $i$ ) The new students lacked the basic knowledge and skills of chemistry experiment operations. Many of the students came from the rural high schools and did not take the chemistry experiment course when they studied in the high schools. They are not familiar with the names and use methods of the basic glassware. (ii) Part of the students are not really interested in the experiment and do not pay attentions to the course. They are not able to do good preview before experiment and carefully do their experiment during the course. (iii) Part of the students could not use the theoretical knowledge learned in the theory teaching to guide their experiments. After the experiments, they could not still completely understand the purpose and principle of the experiment and clearly figure out what they have learnt from the experiment course. (iv) Most of the experiments are verification ones and done based on the textbook.The students'autonomous learning atmosphere has not been yet established. ( $v$ ) Existing evaluation system is not perfect and reasonable. The evaluation is conducted only based on the grade of ordinary times and grade of final experimental examination. These problems seriously affect the teaching quality of FCE course. Several measures are suggested to deal with these problems in order to increase the teaching quality of FCE course in this paper.

\section{I. .INCREASING THE STUDENTS' UNDERSTANDING OF IMPORTANCE OF FCE COURSE}

It is impossible for the students to well learn the FCE course if they lack the understanding of the importance of FCE course[3-4]. For the students who do not attach enough importance to the experiment course, the teachers should educate them to understand the importance of FCE course, actively lead them to set up the correct learning motivation, make them know that they are not only asked to learn a solid theoretical chemistry knowledge, but also master correct and 
practised experimental operation skills, whch is greatly benefit to their future work. In the independent college, the levels of the students are different. There exist certain differences between the students in ideas, knowledge levels, experiment skills, life experiences, thinking abilities, etc.. The teachers should initiatively go deep into the students to communicate with them, realize their thoughts on FCE course, patiently do their ideological work and increase their understanding of the importance of FCE course. In the universities and colleges, the teachers shoulder the dual mandate of imparting knowledge and educating people, so it is very important for the teachers to understand and grasp the students'quality differences, supervise the students ideological work and increase the students' understanding of the importance of FCE course. Under the education of the teachers, the part of students increased their understanding of the importance of FCE course and actively go into the study of the course.

\section{INCREASING THE STUDENTS' INTERESTS IN LEARNING FCE COURSE}

Interest refers to the mood to be fond of or emotional concerns about things. The people psychologically strive to understand something and consciousness tendency of some activity they engage in. It is shown as the people'selective attitude and positive emotional reaction to something and some activities. Interest is greatly important in the human practice activity, which can make the person focus attention and produce happy nervous psychological state. In a words, interest is the source of knowledge and the power of thinking. Therefore, it is important to make the students have great interests in learning FCE course [5-6]. For the students who are not intrested in FCE course or lack the chemistry experiment operation skills, some effective measures are taken to increase their interests in learning FCE corse. Firstly, the teachers teach them to know the importance of learning FCE course and mastering the practical ability for their future career. Secondly, the students are asked to well prepare the preview of each experiment, which includs the understanding of the purpose, principle, chemicals, instruments and operation steps of the experiment. Especially, the teachers require the students to learn and remember the basic operation methods and steps through the textbook, multimedia coursew and video materials before the experiment. During the experiment, the teachers first take a certain time to further explain the operation methods, emphasize the main points of the operations and then personally demonstrate the operations for the students. Thirdly, the teachers always inspect the operations being done by the students. They praise the students when these students have done a standard operation and correctly grasp the experimental skills. They repeatedly and patiently instruct the students with hand when these students are found to have done wrong operations. Fourthly, the teachers require the students to learn from each other and ask the students who have done standard operations to demonstrate the operations for the other students. The measures above greatly improved the students' interests in FCE course and skillfully grasped various of operations, such as titration acid type operation, pipetting operation, subtractive weighing operation, suction filtration operation, distillation operation, thinlayer chromatography analysis, column chromatography analysis and the uses of acidity meter, spectrophotometer and rotary evaporation instrument, etc.

\section{CULTIVATING THE STUDENTS' STUDY STYLE OF COMBINING THEORY WITH PRACTICE}

Scientific theory comes from experiments, accepts the examination from the scientific experiments and, in turn, directs scientific experiments. On the one hand, we are sure that scientific experiment plays an important fundamental role on developing scientific theory, on the other hand, we can not ignore the important guiding function of scientific theory on scientific experiments because designing, conducting, analyzing, summarizing and explaining a scientific experiment can not leave the guidance of scientific theory. Scientific theory provides the principle of scientific experiment and guides scientific experiment. It can be clearly known, from the dialectical relationship between theory and experiment explained above, that it is very important to cultivate a good study style of combining theory with experiment in the teaching of FCE course [7-8]. In our college, both the theoretical and experimental courses of FCE are conducted at the same semester. The university chemistry theoretical and experimental courses are separately conducted in the first semester. The organic chemistry theoretical and experimental courses are carried out at the second semester, respectively. For those students who do not attache great importance to or ignore the theory during their learning FCE course, the teachers repeatedly emphasize the importance of using theory to guide experiments. The students are required to use the theoretical knowledge learnt from the theoretical course to direct their experiments, for example: using the theory knowledge of quantitative analysis in the university chemistry experiments of "The calibration of hydrochloric acid concentration", "The preparation and calibration of EDTA standard solution" and the other experiments related to quantitative analysis; using the theory knowledge of the classification of organic compounds, classification of 
organic reactions and classification of organic reaction mechanism in the organic chemistry experiments of "The synthesis of diphenyl carbinol”, "The preparation of ethyl acetate system" and "The synthesis of amino acid". In order that the students can clearly understand the principles of experiments and theoretically explain various of questions encountered in the experiments, we compiled the "collected questions and answers" including the purpose, principle and the "thinking questions" of each experiment. These documents are loaded on the college network teaching platform. The students can freely download them to read and understand before experiments. During the experiments, the teachers often enlighten and ask the students to see whether they can correctly answer the questions or not. The teachers repeatedly explain the answers with patience when they find some students still have some difficulties. In addition, the teachers require the students to theoretically analyze and discuss their experimental results to find the reasons of success or failue, which is a good way for them to combine theory with practice.

\section{IMPLEMENTING THE MODE OF OPEN EXPERIMENT TEACHING}

The target of universities education is to cultivate the creative talents. The implementation of open experiment teaching is one of the important measures to realize the target[9-10]. The open experiment teaching means that the teachers set the experiment subject for the students to select. The students select the subjects and independently design the experimental schemes through searching literatures. After their experimental schemes are confirmed by the teachers, the students independently build the experimental devices, conduct the operations, treat the experimental dada, calculate the target values, write the experimental reports and report to the teachers by PPT files. The open experiment teaching mode gets rid of the traditional teaching mode of simplely doing verification experiment and realize the shift from the " teachers' teaching as the center" to the " students' autonomous learning as the center ". The types of open experiments involve applied, comprehensive, researching and innovative experiment. The comprehensive experiment is more suitable to the first-year of the college students. In our college, the teachers set 8 of open experiment subjects (comprehensive type) of university chemistry (inorganic chemistry and analytic chemistry) and organic chemistry, respectively. The subjects of open organic chemistry include "The synthesis of paracetamol”, “ The synthesis of dichloro", " The extraction of nicotine from tobacco ", " The extraction of berberine”, “ The preparation of methyl orange”,
“ The preparation of 4-phenyl-2-butanone ", “ The extraction of caffeine from tea " and " The synthesis of benzocaine ". The subjects of open university chemistry experiments include "The preparation of alkali type copper carbonate”, “ The determination of milk acidity and calcium content”, “ The verification of cushion and oxidation reducing", "The formation of coordination compounds and nature". During the open experimental teaching, the subject selection by students, subject confirmation by teachers, asking and answering between students and teachers and PPT report by students are carried out on the network teaching platform of the college. At the present, the open experiment teaching of FCE course is smoothly in the ongoing in our college. It is expected that the high teaching quality of FCE course can be achieved by the open experiment teaching mode.

\section{ESTABLISHING SCIENTIFIC EXPERIMENTAL EVALUATION SYSTEM}

Scientific evaluation system of FCE course contributes to stimulate the students to pay attentions to the FCE course, check the students abilities of analyzing and solving practical problems by means of experiments and promote the improvement of teaching quality of FCE course [11-12]. In order to improve the teaching quality of the FCE course, a set of scientific, reasonable and operational comprehensive evaluation system of FCE course has been established in recent years and being smoothly carried out. The system consists of the assessments of ordinary times, theory examination, operation examination and open experiment examination. The marks of them are $60 \%$, $10 \%, 10 \%$ and $20 \%$ of the total marks(100 marks), respectively. Except of the assessment of ordinary times, the others are newly added in the system. Some students do not pay attentions to the combination of theory with experiment although they have completed their experiments. They could not still understand the principle and answer the "thinking questions of the experiments. For these students, the conduction of theory examination can make them to clearly make out the answers of "thinking questions" listed in the back of each experimen in the textbook through reading the "collection of questions and answers" compiled by the teachers, use the theories to analyze and solve the problems encounted in the experiments and review and solidify the theoretical knowledge before the theory examination. The theory examination is arranged after all the experiments have been finished. The teachers give the note type questions and each student extracts 5 questions to answer by oral or written. Some students do not concentrate on their operations during the experiments and grasp the operation skills at the end of the experiments. For these students, the conduction of 
operation examination can make them carefully and conscientiously understand the operating essentials before the experiments, correctly do their operations during the experiments and repeatedly review each opration they have learned before the operation examination. The operation examination is arranged after all the experiments have been finished. The teachers give the note type questions and each student extracts 5 questions and show their operation performance on the spot. In order to increase the students abilities of autonomous learning and innovation, the open experiment examination are arranged after the compulsory experiments have been finished. In this process, the students are required to select 1 or 2 comprehensive and design experiments and then independently design their experimental schemes through searching literatures. After their schemes are confirmed by the teachers, they independently do the operation, treat the data, figure out the target values, write the paper and PPT report. The marks of open experiment examination include the scheme design (4 marks), specification operation (4 marks), data treatment (4marks), experimental results (4marks) and experimental report (4marks). The open experiment examination not only realzes the switch of the students passive learning to autonomous learning but also increases the students consciousnesses and abilities of innovation.

\section{CONCLUSIONS}

The measures of improving the teaching quality of FCE course are proposed. The implementation of the measures greatly increases the students understanding of the importance of FCE course and interests in learning FCE course, develops the students study style of combining theory with practice, cultivates the students consciousnesses and abilities of innovation and improves the teaching quality of FCE course.

\section{ACKNOWLEDGMENT}

This subject comes from " the Projects on Demonstration Laboratory Construction " financially supported by Nanchang University College of Science and Technology.

\section{REFERENCES}

[1] Jiang Xifu. “ Problems and Countermeasures of Basic Chemistry Experiment Teaching Under the Popular Education”. Education Traching Forum, 2014, issue 5, pp.104-105.

[2] Wan Jian, Song Dandan, Tu Haiyang, et al. “ Developing the students' comprehensive quality in the practice of basic chemistry experiment teaching”. Experimental Technology and
Management, 2012, Vol.29, issue 5, pp. 166-167.

[3] Zhan Haijun, Li Yaping, Tai Xiaojun. "Reform of basic chemistry experiment teaching and improving the quality of experimental teaching”, Laboratory Science, 2006, issue 4, pp.22-25.

[4] Zhou Aiju. " The exploration of enhance the effect of the experimental lessons by strengtheing the preparing lessons". Guangdong Chemical Industry, 2010, Vol.37, issue 203, pp. 222223.

[5] Xie Fazhi, Zhang Fengjun, Xuan Han. “ The reform and practice of teaching quality control in the teaching process of basic chemistry experiment”. Guangdong Chemical Industry, 2012, Vol. 40, issue 8, pp. 191-192,198.

[6] Li Chuanyuan, Ding Weijia, Gu Wenxiang, Yang Zhuohong, Zhang Yaomou. " Methods discussion in improving students studying enthusiasms to fundamental chemistry experiment course”. Guangdong Chemical Industry, 2008, Vol. 35, issue 178, pp. 83-84.

[7] Guo Xiulan, He Tingyu, Zeng Manzhi, Xu Li, Luo Zhigang. "Experience and suggestion to improve quality of the teaching of fundamental chemistry experiment course”.Guangdong Chemical Industry, 2009, Vol. 36, issue 193, pp. 204-206.

[8] Chen Ningyu, Wang Zhiqun. “ Teaching reforms and research for proggamming courses based on ACM/ICPC model”. Journal of Huzhou Teachers College, 2012, Vol.34, issue 2, pp. 119121,130 .

[9] Li guoxiang, Li songbo. "Study and exploration of open teaching mode of basic chemistry experiment”. Inner Mongolia petrochemical industry, 2007, issue 1, pp.21-22.

[10] Xu Yaqin, Fu Ying. "Research and exploration of openchemistry experiments”. Experimental technology and management, 2007, issue 2, pp. 14-15.

[11] Xu Ling, Wang Ying, Hu Hanmei, Wu Shibiao, Zhang Yan, Liu Jin. " Exploration \& practice on improving experiment teaching quality of basic chemistry”. Journal of Hefei Normal University, 2013, Vol. 31, issue 3. pp. 92-93.

[12] Wu Shibiao, Wang Ying, Xu Haiyan, et al.. "The new exploration on guaranteeing the teaching quality of basic chemical experiment”. Journal of Hefei Normal University, 2010, issue 3. pp. 91-93. 